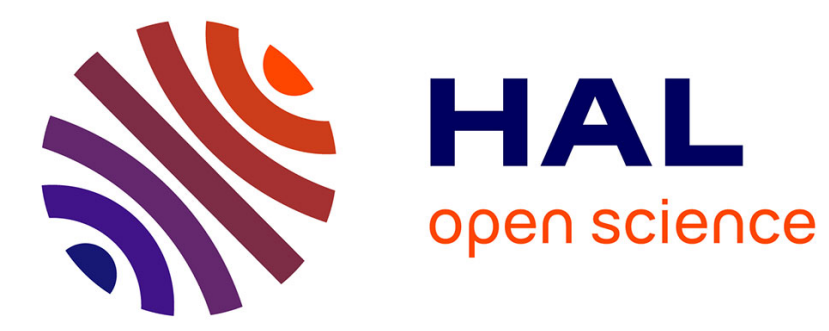

\title{
Sub-50 fs pulse generation from a SESAM mode-locked Tm,Ho-codoped calcium aluminate laser
}

Li Wang, Weidong Chen, Yongguang Zhao, Pavel Loiko, Xavier Mateos, Mircea Guina, Zhongben Pan, Mark Mero, Uwe Griebner, Valentin Petrov

\section{- To cite this version:}

Li Wang, Weidong Chen, Yongguang Zhao, Pavel Loiko, Xavier Mateos, et al.. Sub-50 fs pulse generation from a SESAM mode-locked Tm,Ho-codoped calcium aluminate laser. Optics Letters, 2021, 46 (11), pp.2642. 10.1364/OL.426113 . hal-03345697

\section{HAL Id: hal-03345697 \\ https://hal.science/hal-03345697}

Submitted on 12 Oct 2021

HAL is a multi-disciplinary open access archive for the deposit and dissemination of scientific research documents, whether they are published or not. The documents may come from teaching and research institutions in France or abroad, or from public or private research centers.
L'archive ouverte pluridisciplinaire HAL, est destinée au dépôt et à la diffusion de documents scientifiques de niveau recherche, publiés ou non, émanant des établissements d'enseignement et de recherche français ou étrangers, des laboratoires publics ou privés. 


\title{
Sub-50-fs pulse generation from a SESAM mode- locked Tm,Ho-codoped calcium aluminate laser
}

\author{
LI Wang, ${ }^{1}$ Weidong Chen,,${ }^{1,2, *}$ Yongguang ZhaO, ${ }^{1}$ Zhongben Pan, $, 1,7$ \\ Pavel loiko, ${ }^{3}$ Xavier Mateos, ${ }^{4,5}$ Mircea Guina, ${ }^{6}$ Mark Mero, ${ }^{1}$ \\ UWe Griebner, ${ }^{1}$ And Valentin Petrov ${ }^{1}$
}

\author{
${ }^{1}$ Max Born Institute for Nonlinear Optics and Short Pulse Spectroscopy, Max-Born-Str. 2a, 12489 Berlin, Germany \\ ${ }^{2}$ Key Laboratory of Optoelectronic Materials Chemistry and Physics, Fujian Institute of Research on the Structure of Matter, Chinese Academy \\ of Sciences, Fuzhou, 350002 Fujian, China \\ ${ }^{3}$ Centre de Recherche sur les lons, les Matériaux et la Photonique (CIMAP), UMR 6252 CEA-CNRS-ENSICAEN, Université de Caen, 6 Boulevard \\ du Maréchal Juin, 14050 Caen Cedex 4, France \\ ${ }^{4}$ Universitat Rovira i Virgili (URV), Física i Cristal-lografia de Materials i Nanomaterials (FiCMA-FiCNA), 43007 Tarragona, Spain \\ ${ }^{5}$ Serra Húnter Fellow \\ ${ }^{6}$ Reflektron Ltd., Muotialankuja 5 C5, Tampere 33800, Finland \\ 7pzb8625@126.com \\ *Corresponding author: chenweidong@fjirsm.ac.cn
}

Received XX Month XXXX; revised XX Month, XXXX; accepted XX Month XXXX; posted XX Month XXXX (Doc. ID XXXXX); published XX Month XXXX

\begin{abstract}
We report on sub-50-fs pulse generation from a passively mode-locked Tm,Ho-codoped crystalline laser operating in the $2 \mu \mathrm{m}$ spectral region. A Tm,Ho:Ca(Gd,Lu)AlO ${ }_{4}$ laser delivers pulses as short as $46 \mathrm{fs}$ at $2033 \mathrm{~nm}$ with an average power of $121 \mathrm{~mW}$ at a pulse repetition rate of $\sim 78 \mathrm{MHz}$ employing a SESAM as a saturable absorber. To the best of our knowledge, this result represents the shortest pulses ever generated from a Tm and/or Ho based solid-state laser. Polarization switching in the anisotropic gain material is observed in the mode-locked regime without any polarization selection elements which is essential for the shortest pulses. (C) 2021 Optical Society of America.
\end{abstract}

http://dx.doi.org/10.1364/OL.99.099999

During the last few years there has been a rapid progress in the generation of sub-100-fs pulses in the $2-\mu \mathrm{m}$ spectral region directly from mode-locked (ML) lasers based on thulium $\left(\mathrm{Tm}^{3+}\right)$ and/or holmium $\left(\mathrm{Ho}^{3+}\right)$ doped active media [1]. Apart from direct spectroscopic or diagnostic applications, such high-repetition rate laser sources are important for seeding of ultrafast (chirped-pulse) laser amplifiers and synchronous pumping of optical parametric oscillators operating in the mid-IR spectral range based on nonoxide nonlinear materials with high conversion efficiency [2]. By entering the few optical cycle regime, they can also become a viable alternative to complex and inefficient coherent sources based on optical rectification for seeding of carrier-envelope phase (CEP) stable systems [3]. $\mathrm{Ho}^{3+}$-doped laser materials feature the merits of natural emission slightly above $2 \mu \mathrm{m}$ to overcome the detrimental structured water vapor absorption/dispersion effect below $2 \mu \mathrm{m}$, and somewhat higher gain compared to their Tm-doped counterparts. Nevertheless, their spectrally structured gain profiles place limitations on the pulse duration achievable from singly Hodoped ML femtosecond lasers. This problem can be partially resolved by co-doping with $\mathrm{Tm}^{3+}$. The gain profiles of $\mathrm{Ho}^{3+}$ and $\mathrm{Tm}^{3+}$ in co-doped materials are overlapping, which makes it possible to combine their stimulated emissions and support ultrabroad spectra in the ML regime [4]. Efforts toward exploiting the gain bandwidth of Tm,Ho co-doped bulk gain media resulted in the first sub- $100 \mathrm{fs}$ pulse operation in a ML 2- $\mu$ m solid-state laser in 2018. Using a SEmiconductor Saturable Absorber Mirror (SESAM) as a modelocker, pulses as short as $87 \mathrm{fs}$ with an average power of $27 \mathrm{~mW}$ were generated with Tm,Ho:CaYAlO 4 (Tm,Ho:CALYO) [5]. Subsequently, shorter pulses (70 and $67 \mathrm{fs}$ ) were obtained with a Tm,Ho co-doped garnet crystal, i.e., Tm,Ho: $\mathrm{Ca}_{3} \mathrm{Li}_{\mathrm{X}} \mathrm{Nb}_{1.5+\mathrm{x}} \mathrm{Ga}_{3.5-2 x} \mathrm{O}_{12}$ (Tm,Ho:CLNGG), and carbon nanostructures as saturable absorbers (SAs) [6, 7]. Finally, a pulse duration of $52 \mathrm{fs}$ at $2015 \mathrm{~nm}$ was demonstrated using a Tm,Ho: $\mathrm{CaGdAlO}_{4}$ (Tm,Ho:CALGO) crystal and a SESAM SA [8].

The above achievements profited from the inhomogeneous spectral broadening of the gain profiles originating from the structural disorder and the related ligand modifications of the host crystals employed. Tetragonal rare-earth calcium aluminates $\mathrm{CaLnAlO}_{4}(\mathrm{Ln}=\mathrm{Gd}, \mathrm{Y})$ represent such an extraordinarily disordered host family which is extremely favorable for femtosecond pulse generation. Their structural disorder originates from the second coordination sphere of the laser-active trivalent rare-earth $\left(\mathrm{RE}^{3+}\right.$, e.g., $\mathrm{Yb}^{3+}, \mathrm{Tm}^{3+}$ and $\mathrm{Ho}^{3+}$ ) cations formed by $\mathrm{Ca}^{2+}$ and $\mathrm{Ln}^{3+}$ ions 


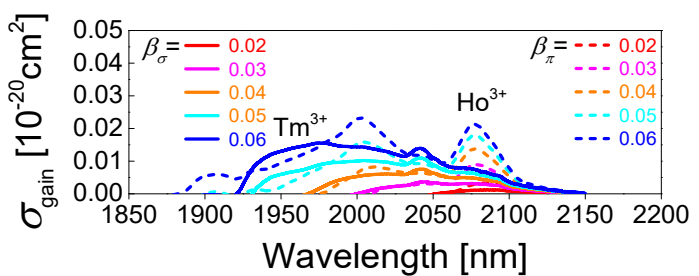

Fig. 1. Effective gain cross-section spectra at $\sim 2 \mu \mathrm{m}$ for the Tm,Ho:CALGLO crystal, $\beta=N\left({ }^{3} \mathrm{~F}_{4}\right) / N_{\mathrm{Tm}}$ is the inversion ratio for $\mathrm{Tm}^{3+}$ ions, the polarization is $\sigma$ (solid lines) and $\pi$ (dashed lines).

(due to the charge difference of these ions and the different cationcation distances) [9]. Despite the disordered structure, $\mathrm{CaLnAlO}_{4}$ still exhibit relatively high thermal conductivity with moderate dependence on the $\mathrm{RE}^{3+}$ doping concentration [10]. In comparison to the disordered garnets, the polarized absorption and emission of the tetragonal calcium aluminates offer more flexibility in pumping and spectral bandwidth exploitation. Moreover, the structural disorder of the $\mathrm{CaLnAlO}_{4}$ compounds can be complemented by compositional disorder leading to additional inhomogeneous spectral broadening, smoothing and flattening of the gain profiles of the optically active $\mathrm{RE}^{3+}$ ions [11]. The latter is achievable by mixing CALGO and CALYO or by Lu-doping of one of them. Such compositional disorder with partial substitution of $\mathrm{Gd}^{3+}$ by $\mathrm{Lu}^{3+}(\mathrm{a}$ maximum $\mathrm{Lu}^{3+}$ content of 5.5 at.\%) was firstly utilized for $\mathrm{Yb}^{3+}$ doped $\mathrm{Ga}(\mathrm{Gd}, \mathrm{Lu}) \mathrm{AlO}_{4}(\mathrm{Yb}: \mathrm{CALGLO})$ and laser operation both in the continuous-wave (CW) and femtosecond ML regimes was demonstrated [12]. Very recently, we reported on $\mathrm{Tm}^{3+}$-doping of this novel mixed host crystal, Tm:CALGLO, its growth, spectroscopy, and CW laser operation [13].

Recently, such Tm,Ho co-doping structurally and compositionally disordered "mixed" co-doped crystal, Tm,Ho:CALGLO, were grown with high optical quality by its growth using the Czochralski method [14]. The measured doping levels were 4.48 at. $\% \mathrm{Tm}^{3+}, \quad 0.54$ at. $\% \mathrm{Ho}^{3+}$ and 5.51 at.\% $\mathrm{Lu}^{3+}$, corresponding to a stoichiometric chemical formula of $\mathrm{CaGd}_{0.8947} \mathrm{Lu}_{0.0551} \mathrm{Tm}_{0.0448} \mathrm{Ho}_{0.0054} \mathrm{AlO}_{4}$. The tetragonal Tm,Ho:CALGLO is an optically uniaxial crystal with two principal polarizations, i.e. $E \| c$ ( $\pi$-polarization) and $E \| a$ ( $\sigma$-polarization) with the corresponding refractive indices $n_{\mathrm{e}}$ and $n_{\mathrm{o}}$. The calculated gain cross-sections of Tm,Ho:CALGLO for both polarizations with different Tm inversion levels $\beta$ are shown in Fig. 1 . The crystal features an extremely broad and smooth spectral gain profile supporting sub-50-fs pulses. The excellent spectroscopic and thermo-mechanical properties of Tm,Ho:CALGLO are attractive for passively ML operation in the $2-\mu \mathrm{m}$ spectral region. Implementing a GaSb-based SESAM for mode locking, and broadband dispersive mirrors (DMs) for intracavity group delay dispersion (GDD) management, we report here on the generation of pulses as short as $46 \mathrm{fs}$, the shortest to date, to the best of our knowledge, for any Tm and/or Ho based solid-state mode-locked laser.

Laser operation was investigated in a X-folded standing-wave cavity without any polarization selecting elements, as shown in Fig. 2. The Tm,Ho:CALGLO crystal was an $\boldsymbol{a}$-cut cube with an edge of $3 \mathrm{~mm}$ which was anti-reflection coated for normal incidence for both the pump and laser wavelengths. It was mounted in a copper holder water-cooled at $12^{\circ} \mathrm{C}$, and placed between two dichroic folding mirrors $\mathrm{M}_{1}$ and $\mathrm{M}_{2}$ with a Radius of Curvature (RoC) of $100 \mathrm{~mm}$. A third folding mirror $\left(\mathrm{DM}_{1}, \mathrm{RoC}=-100 \mathrm{~mm}\right)$ provided a second cavity beam waist in one of the cavity arms where the

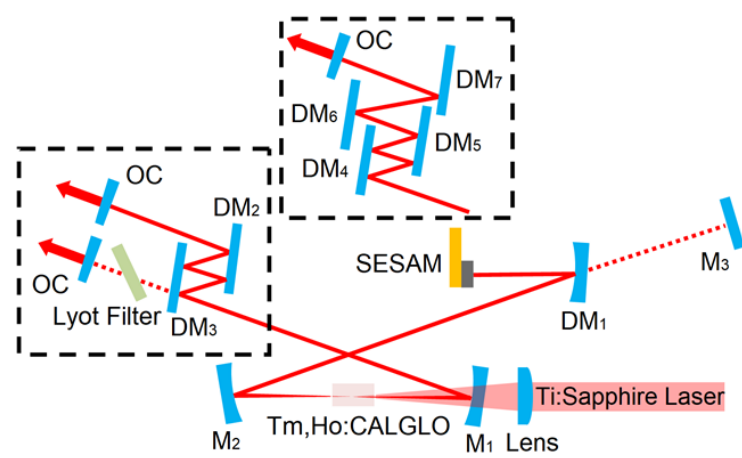

Fig. 2. Experimental scheme of the SESAM ML Tm,Ho:CALGLO laser, Lens: focusing lens; $\mathrm{M}_{1}-\mathrm{M}_{2}$ : concave mirrors; $\mathrm{DM}_{1}-\mathrm{DM}_{7}$, dispersive mirrors; OC: output coupler; $\mathrm{M}_{3}$ : plane mirror for $\mathrm{CW}$ operation.

SESAM was implemented. The output coupler (OC) terminated the other cavity arm. The radius of the cavity mode in the crystal was estimated to be $30 \mu \mathrm{m}$ by the ABCD formalism. The Tm,Ho:CALGLO crystal was pumped by a narrow-linewidth CW Ti:sapphire laser tuned to $801.3 \mathrm{~nm}$ with its polarization corresponding to $\pi$ in the crystal to utilize the much higher absorption cross-section [12]. A spherical lens with a focal length of $70 \mathrm{~mm}$ focused the pump beam into the crystal yielding a waist radius of $30 \mu \mathrm{m}$. The measured single-pass absorption was $\sim 97 \%$ under lasing conditions. A maximum CW power of $778 \mathrm{~mW}$ was extracted for an absorbed power of $3.09 \mathrm{~W}$ using the 3\% OC and the SESAM substituted by a plane retroreflector, cf. Fig. 2 . The corresponding slope efficiency was $\sim 35.8 \%$. The laser output was $\pi$-polarized.

A GaSb-based InGaAsSb quantum wells (QWs) SESAM was applied as a mode-locker. Such a near-surface QW design SESAM has been already successfully applied for the generation of sub$100 \mathrm{fs}$ pulses at $\sim 2 \mu \mathrm{m}[15,16]$ and the characteristic parameters can be found elsewhere [17]. It was placed at the second beam waist for efficient bleaching of the SA. The estimated radius of this beam waist was $\sim 120 \mu \mathrm{m}$. The intracavity GDD was managed by the DMs, one curved $\left(\mathrm{DM}_{1}\right)$ and several flat $\left(\mathrm{DM}_{2}-\mathrm{DM}_{7}\right)$. All DMs exhibited a GDD of $-125 \mathrm{fs}^{2}$ per bounce. The total negative GDD introduced was varied by the number of bounces on the flat DMs to balance the intracavity material dispersion as well as the positive frequency chirp induced by self-phase modulation (SPM) in ML operation. Three different OCs (3\%, 1.5\% and 0.5\%) were applied. A 3-mm thick $\mathrm{ZnS}$ ceramic plate (GDD $\left.=465 \mathrm{fs}^{2}\right)$ was used for external linear chirp compensation of the extra GDD introduced by the OC substrate $\left(6.35-\mathrm{mm}\right.$ thick infrasil, GDD $\left.=-684 \mathrm{fs}^{2}\right)$.

Initially, ML operation was investigated by applying five bounces (single pass) on the flat DMs $\left(\mathrm{DM}_{1}-\mathrm{DM}_{3}\right)$ giving a total round-trip GDD of $-1250 \mathrm{fs}^{2}$. Using the 3\% OC, stable soliton ML operation was initiated and stabilized by the SESAM for a nominal pump level of $3 \mathrm{~W}$. The laser generated an output power of $320 \mathrm{~mW}$ at $2081 \mathrm{~nm}$ in $\pi$-polarization. The 306-fs pulses, assuming a sech ${ }^{2}$-shape temporal profile, had a sech ${ }^{2}$-fitted spectral FWHM of $15 \mathrm{~nm}$. Optimizing the cavity alignment for shorter pulse durations, we observed substantial broadening of the ML spectrum as well as a blue shift of the central wavelength accompanied by switching to linear $\sigma$-polarization. A maximum average power of $332 \mathrm{~mW}$ was obtained at optimum alignment for an absorbed pump power of $3.53 \mathrm{~W}$. The measured ML spectrum and the corresponding interferometric autocorrelation trace at this output level are shown in Fig. 3. Almost bandwidth-limited pulses with a duration of $69 \mathrm{fs}$ 

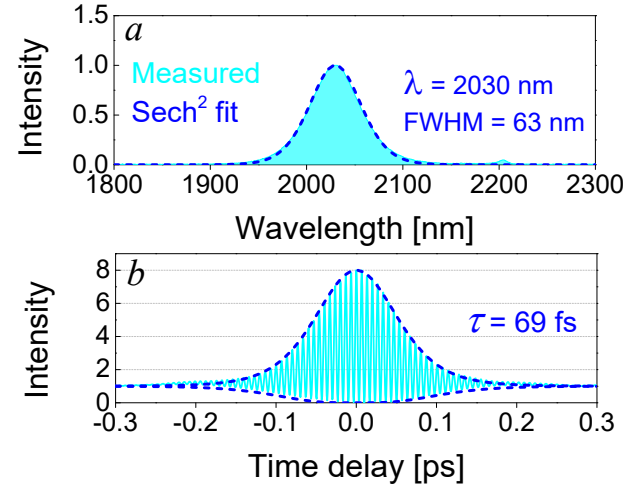

Fig. 3. (a) Optical spectrum and (b) interferometric autocorrelation trace of the SESAM ML Tm,Ho:CALGLO laser for $T o c=3 \%$.

were achieved while the spectral FWHM was $63 \mathrm{~nm}$. The peak power amounted to $53 \mathrm{~kW}$ for a pulse repetition rate of $82.9 \mathrm{MHz}$. The laser was always self-starting.

Such polarization switching has been reported in a diodepumped high-power Yb:CALGO laser in the CW regime, where the gain cross-sections for the two polarizations are similar in magnitude and hence compete at different inversion rates if the cavity loss is changing owing to the different thermo-optical properties of the laser crystal for $\pi$ and $\sigma$-polarizations [18]. ML lasers are even more for sensitive to cavity losses which supports a similar explanation for the present Tm,Ho:CALGLO laser. We are not aware of any similar observations in a ML solid-state laser.
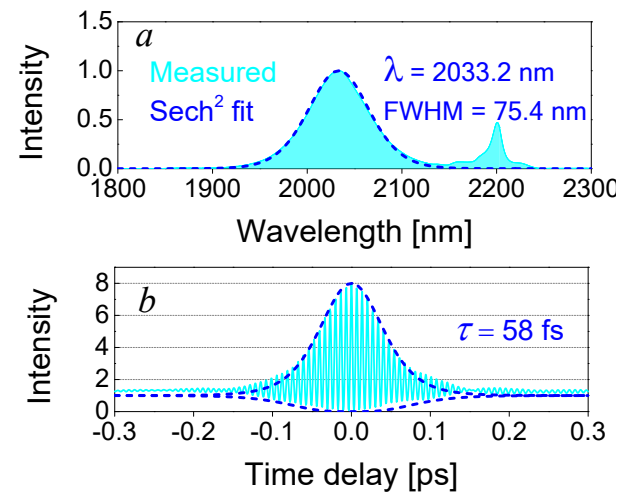

Fig. 4. (a) Optical spectrum and (b) interferometric autocorrelation trace of the SESAM ML Tm,Ho:CALGLO laser for Toc $=1.5 \%$.

The pulse duration was further reduced to $58 \mathrm{fs}$ by applying the $1.5 \%$ OC. As can be expected for a three-level system, the wavelength experienced a slight red-shift, in our case to $2033.2 \mathrm{~nm}$, see Fig. 4 , maintaining the $\sigma$-polarization. The average power amounted to $191 \mathrm{~mW}$ at $82.9 \mathrm{MHz}$ for an absorbed pump power of $3.23 \mathrm{~W}$. In this configuration the estimated pulse duration from the interferometric autocorrelation trace was $45 \%$ above the Fourier limit, which means that the intracavity DMs were unable to ensure effective soliton compression, i.e., more negative GDD was required for further shortening of the pulse duration.

The latter was realized using seven instead of five bounces (single pass) on DMs (cf. Fig. 2) resulting in a total round-trip GDD of $1750 \mathrm{fs}^{2}$. The shortest single pulse operation with ultimate stability in this case was achieved using the $0.5 \% \mathrm{OC}$, again in $\sigma$-polarization.
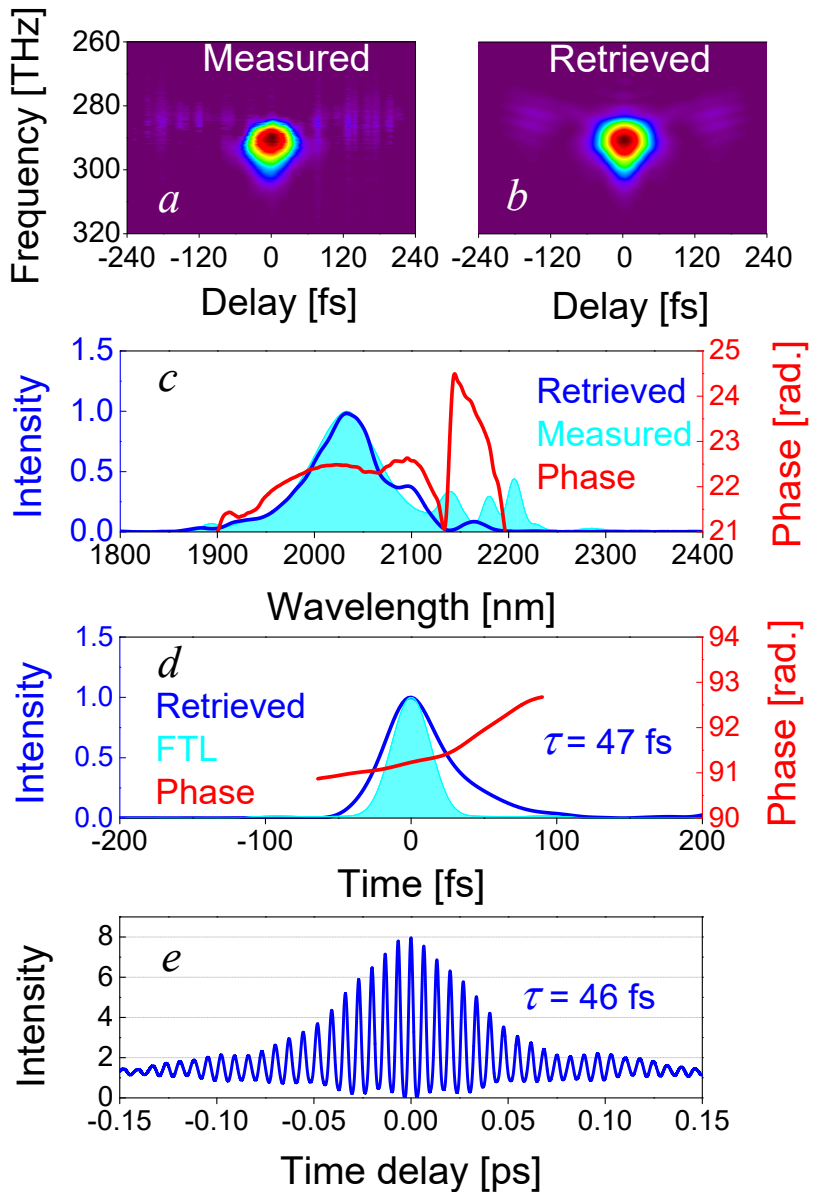

Fig. 5. SHG-FROG characterization of the shortest pulses from the SESAM ML Tm,Ho:CALGLO laser for Toc $=0.5 \%$. Measured (a) and retrieved (b) SHG-FROG traces; measured and retrieved optical spectrum and its spectral phase (c); Fourier-transform limited (FTL) and retrieved temporal pulse profile and phase (d); measured interferometric autocorrelation trace (e).

A maximum average power of $121 \mathrm{~mW}$ at $78.2 \mathrm{MHz}$ was generated for an absorbed power of $3.78 \mathrm{~W}$. The shortest pulses were characterized using a second-harmonic generation (SHG) frequency-resolved optical gating (FROG) apparatus. The measured and retrieved SHG-FROG traces using a grid size of $512 \times 512$ points together with the reconstructed spectral and temporal profiles are shown in Figs. 5 (a) and (b). The directly measured spectrum was centered at $2033 \mathrm{~nm}$ spanning from 1878 to $2241 \mathrm{~nm}$, in reasonably good agreement with the reconstructed spectrum from the SHG-FROG trace, cf. Fig.5(c). After external linear chirp compensation with the 3-mm thick $\mathrm{ZnS}$ ceramic plate, the retrieved pulse had a FWHM of $47 \mathrm{fs}$ ( $\sim 7$ optical cycles), still $\sim 38 \%$ above the Fourier-limit, cf. Fig. 5(d). The retrieved pulse duration was confirmed by an independent measurement of the autocorrelation trace, giving a FWHM of 46 fs, see Fig. 5(e).

The far-field beam profiles for CW and ML operation were recorded with a pyroelectric camera placed at $1.6 \mathrm{~m}$ from the OC, see Fig. 6. Almost no changes were observed when switching from the CW to ML operation, easily achievable by slight misalignment. This observation indicates that Kerr-lensing is not the dominant mechanism for mode-locking which is mainly governed by soliton pulse shaping, stabilized by the SESAM. 

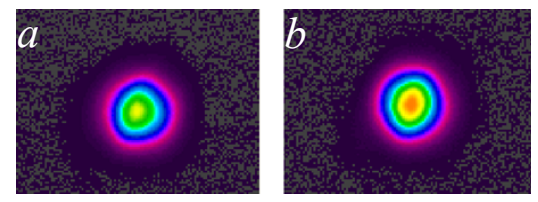

Fig. 6. ML Tm,Ho:CALGLO laser: far-field beam profiles in (a) CW and (b) SESAM ML regimes.

The steady-state pulse train was characterized by a radiofrequency analyzer. Figures 7 (a) and (b) show the first beat-note at $\sim 78.2 \mathrm{MHz}$ with a signal-to-noise ratio above $70 \mathrm{dBc}$ and a $1-\mathrm{GHz}$ span, both indicating stable ML operation without any spurious modulations.
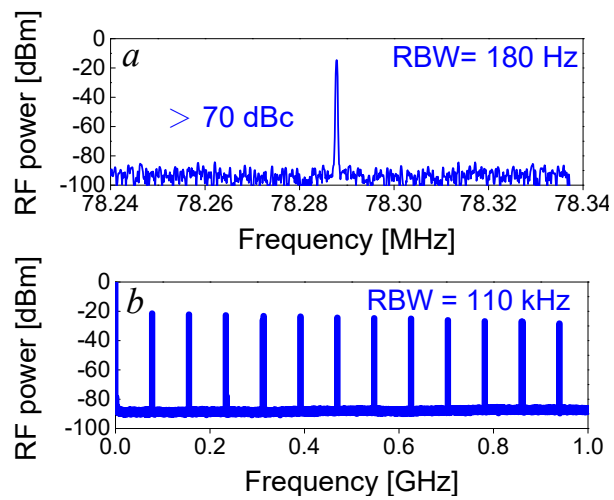

Fig. 7. Radio-frequency spectra of the SESAM ML Tm,Ho:CALGLO laser: (a) fundamental beat note at $78.2 \mathrm{MHz}$ measured with a resolution bandwidth (RBW) of $180 \mathrm{~Hz}$, and (b) harmonics on a 1-GHz span, measured with a RBW of $110 \mathrm{kHz}$.

In conclusion, we achieved sub-50 fs pulses in the $2-\mu \mathrm{m}$ spectral region from a ML laser by exploring Tm,Ho co-doping of the mixed CALGLO crystal. Using a GaSb-based SESAM as a SA pulses as short as $46 \mathrm{fs}$ were recorded, the shortest ever reported for any Tm and/or Ho based solid-state laser. Without any intracavity polarization selective elements, we observed polarization switching related to the anisotropy of the gain medium and triggered by changing the cavity losses (note that the polarization was always linear). Switching from $\pi$ to $\sigma$-polarization was associated with spectral broadening and hence the generation of the shortest pulses. This switching was accompanied by a blue shift of the central wavelength. This regime was readily achievable by minimizing the cavity losses and by careful cavity alignment independent of the OC transmission or the pump level. Note that imposing the $\sigma$-polarization simply by the Brewster angle condition for the active medium or taking a $\boldsymbol{c}$-cut crystal is not practical for the present laser because pumping in $\pi$-polarization is much more effective.

Funding. National Natural Science Foundation of China (61975208, 51761135115, 61575199, 61850410533, 62075090, 52032009, 52072351); Deutsche Forschungsgemeinschaft (PE 607/14-1); Sino-German Scientist Cooperation and Exchanges Mobility Program (M-0040); Foundation of the President of China Academy of Engineering Physics (YZJJLX2018005); Foundation of Key Laboratory of Optoelectronic Materials Chemistry and Physics, Chinese Academy of Sciences (2008DP173016); Foundation of
State Key Laboratory of Crystal Materials, Shandong University (KF2001).

Disclosures. The authors declare no conflicts of interest.

Data Availability. Data supporting the findings presented in this paper are not publicly available at this time but may be obtained from the corresponding author upon reasonable request.

\section{References}

1. V. Petrov, Y. Wang, W. Chen, Z. Pan, Y. Zhao, L. Wang, M. Mero, S. Y. Choi, F. Rotermund, and W. B. Cho, Proc. SPIE 11209, 112094G (2020).

2. V. Petrov, Prog. Quantum. Electron. 42, 1 (2015).

3. T. Fuji, N. Ishii, C. Y. Teisset, X. Gu, T. Metzger, A. Baltuska, N. Forget, D. Kaplan, A. Galvanauskas, and F. Krausz, Opt. Lett. 31, 1103 (2006).

4. Z. Pan, P. Loiko, Y. Wang, Y. Zhao, H. Yuan, K. Tang, X. Dai, H. Cai, J. M. Serres, S. Slimi, E. Ben Salem, E. Dunina, A. Kornienko, L. Fomicheva, J.-L. Doualan, P. Camy, W. Chen, U. Griebner, V. Petrov, M. Aguiló, F. Díaz, R. M. Solé, and X. Mateos, J. Alloys Compd. 853, 157100 (2021).

5. Y. Zhao, Y. Wang, X. Zhang, X. Mateos, Z. Pan, P. Loiko, W. Zhou, X. Xu, J. Xu, D. Shen, S. Suomalainen, A. Härkönen, M. Guina, U. Griebner, and V. Petrov, Opt. Lett. 43, 915 (2018).

6. Z. Pan, Y. Wang, Y. Zhao, M. Kowalczyk, J. Sotor, H. Yuan, Y. Zhang, X. Dai, H. Cai, J. E. Bae, S. Y. Choi, F. Rotermund, P. Loiko, J. M. Serres, X. Mateos, U. Griebner, and V. Petrov, Opt. Lett. 43, 5154 (2018).

7. Y. Zhao, Y. Wang, W. Chen, Z. Pan, L. Wang, X. Dai, H. Yuan, Y. Zhang, H. Cai, J. E. Bae, S. Y. Choi, F. Rotermund, P. Loiko, J. M. Serres, X. Mateos, W. Zhou, D. Shen, U. Griebner, and V. Petrov, Opt. Express 27, 1922 (2019).

8. Y. Wang, Y. Zhao, P. Loiko, Z. Pan, W. Chen, M. Mero, X. Xu, J. Xu, X. Mateos, A. Major, S. Suomalainen, A. Härkönen, M. Guina, U. Griebner, and V. Petrov, in Laser Congress 2019 (ASSL, LAC, LS\&C)(Optical Society of America, Washington, DC, 2019), p. AM3A.7.

9. S. Kimura, S. Tani, and Y. Kobayashi, Sci. Rep. 93738 (2019).

10. P. Loiko, F. Druon, P. Georges, B. Viana, and K. Yumashev, Opt.Mater. Express 4, 2241 (2014).

11. V. Lupei, A. Lupei, C. Gheorghe, L. Gheorghe, A. Achim, and A. Ikesue, J. Appl. Phys. 112, 063110 (2012).

12. Q. Hu, X. Su, Y. Wang, J. He, B. Zhang, Z. Jia, and X. Tao, Laser Phys. Lett. 14, 045809 (2017).

13. Z. Pan, P. Loiko, J. M. Serres, E. Kifle, H. Yuan, X. Dai, H. Cai, Y. Wang, Y. Zhao, M. Aguiló, F. Díaz, U. Griebner, V. Petrov, and X. Mateos, Opt. Express 27, 9987 (2019).

14. Z. Pan, P. Loiko, J. M. Serres, E. Kifle, H. Yuan, X. Dai, H. Cai, Y. Wang, Y. Zhao, R. M. Sole, M. AguilO, F. Diaz, P. Camy, E. Dunina, A. Kornienko, U. Griebner, V. Petrov, and X. Mateos, in Conference on Lasers and Electro-Optics (Optical Society of America, Washington, DC, 2020), p. SM3E.6.

15. Y. Zhao, L. Wang, W. Chen, Z. Pan, Y. Wang, P. Liu, X. Xu, Y. Liu, D. Shen, J. Zhang, M. Guina, X. Mateos, P. Loiko, Z. Wang, X. Xu, J. Xu, M. Mero, U. Griebner, and V. Petrov, Appl. Optics 59, 10493 (2020).

16. Y. Wang, W. Jing, P. Loiko, Y. Zhao, H. Huang, X. Mateos, S. Suomalainen, A. Härkönen, M. Guina, U. Griebner, and V. Petrov, Opt. Express 26, 10299 (2018).

17. J. Paajaste, S. Suomalainen, A. Härkönen, U. Griebner, G. Steinmeyer, and M. Guina, J. Phys. D. 47, 065102 (2014).

18. F. Druon, M. Olivier, A. Jaffrès, P. Loiseau, N. Aubry, J. DidierJean, F. Balembois, B. Viana, and P. Georges, Opt. Lett. 38, 4138 (2013). 


\section{References}

1. V. Petrov, Y. Wang, W. Chen, Z. Pan, Y. Zhao, L. Wang, M. Mero, S. Y. Choi, F. Rotermund, W. B. Cho, W. Jing, H. Huang, H. Yuan, H. Cai, L. Zhang, Z. Lin, P. Loiko, X. Mateos, X. Xu, J. Xu, H. Yu, H. Zhang, S. Suomalainen, M. Guina, A. Härkönen, and U. Griebner, Sub-100-fs bulk solidstate lasers near 2-micron (SPIE, 2019).

2. V. Petrov, "Frequency down-conversion of solid-state laser sources to the mid-infrared spectral range using non-oxide nonlinear crystals," Progress in Quantum Electronics 42, 1-106 (2015).

3. T. Fuji, N. Ishii, C. Y. Teisset, X. Gu, T. Metzger, A. Baltuska, N. Forget, D. Kaplan, A. Galvanauskas, and F. Krausz, "Parametric amplification of few-cycle carrier-envelope phase-stable pulses at $2.1 \mu \mathrm{m}$," Optics Letters 31, 1103-1105 (2006).

4. Z. Pan, P. Loiko, Y. Wang, Y. Zhao, H. Yuan, K. Tang, X. Dai, H. Cai, J. M. Serres, S. Slimi, E. Ben Salem, E. Dunina, A. Kornienko, L. Fomicheva, J.L. Doualan, P. Camy, W. Chen, U. Griebner, V. Petrov, M. Aguiló, F. Díaz, R. M. Solé, and X. Mateos, "Disordered Tm3+,Ho3+-codoped CNGG garnet crystal: Towards efficient laser materials for ultrashort pulse generation at $\sim 2 \mu \mathrm{m}$," Journal of Alloys and Compounds 853, 157100 (2021).

5. Y. Zhao, Y. Wang, X. Zhang, X. Mateos, Z. Pan, P. Loiko, W. Zhou, X. Xu, J. Xu, D. Shen, S. Suomalainen, A. Härkönen, M. Guina, U. Griebner, and V. Petrov, "87 fs mode-locked Tm,Ho:CaYAlO4 laser at $\sim 2043 \mathrm{~nm}$," Optics Letters 43, 915-918 (2018).

6. Z. Pan, Y. Wang, Y. Zhao, M. Kowalczyk, J. Sotor, H. Yuan, Y. Zhang, X. Dai, H. Cai, J. E. Bae, S. Y. Choi, F. Rotermund, P. Loiko, J. M. Serres, X. Mateos, U. Griebner, and V. Petrov, "Sub-80 fs mode-locked Tm,Hocodoped disordered garnet crystal oscillator operating at $2081 \mathrm{~nm}$," Optics Letters 43, 5154-5157 (2018).

7. Y. Zhao, Y. Wang, W. Chen, Z. Pan, L. Wang, X. Dai, H. Yuan, Y. Zhang, H. Cai, J. E. Bae, S. Y. Choi, F. Rotermund, P. Loiko, J. M. Serres, X. Mateos, W. Zhou, D. Shen, U. Griebner, and V. Petrov, "67-fs pulse generation from a mode-locked Tm,Ho:CLNGG laser at $2083 \mathrm{~nm}$," Optics Express 27, 1922-1928 (2019).

8. Y. Wang, Y. Zhao, P. Loiko, Z. Pan, W. Chen, M. Mero, X. Xu, J. Xu, $X$. Mateos, A. Major, S. Suomalainen, A. Härkönen, M. Guina, U. Griebner, and V. Petrov, "52-fs SESAM Mode-Locked Tm,Ho:CALGO Laser," in Laser Congress 2019 (ASSL, LAC, LS\&C)(Optical Society of America, Vienna, 2019), p. АM3A.7.

9. S. Kimura, S. Tani, and Y. Kobayashi, "Raman-assisted broadband mode-locked laser," Scientific Reports 9 (2019).

10. P. Loiko, F. Druon, P. Georges, B. Viana, and K. Yumashev, "Thermo-optic characterization of $\mathrm{Yb}: \mathrm{CaGdAlO}_{4}$ laser crystal," Optical Materials Express 4, 2241-2249 (2014).

11. V. Lupei, A. Lupei, C. Gheorghe, L. Gheorghe, A. Achim, and A. Ikesue, "Crystal field disorder effects in the optical spectra of $\mathrm{Nd}^{3+}$ and $\mathrm{Yb}^{3+}$ doped calcium lithium niobium gallium garnets laser crystals and ceramics," Journal of Physics D: Applied Physics 112, 063110 (2012).

12. H. Qiangqiang, S. Xiancui, W. Yiran, H. Jingliang, Z. Baitao, J. Zhitai, and T. Xutang, "Spectroscopic properties and ultrafast performance of $\mathrm{Yb}: \mathrm{CaLu}_{x} \mathrm{Gd}_{1-\mathrm{x}} \mathrm{AlO}_{4}$ crystal," Laser Physics Letters 14, 045809 (2017).

13. Z. Pan, P. Loiko, J. M. Serres, E. Kifle, H. Yuan, X. Dai, H. Cai, Y. Wang, Y. Zhao, M. Aguiló, F. Díaz, U. Griebner, V. Petrov, and X. Mateos, "“Mixed" Tm: $\mathrm{Ca}(\mathrm{Gd}, \mathrm{Lu}) \mathrm{AlO}_{4}-$ a novel crystal for tunable and mode-locked $2 \mu \mathrm{m}$ lasers," Optics Express 27, 9987-9995 (2019).

14. Z. Pan, P. Loiko, J. M. Serres, E. Kifle, H. Yuan, X. Dai, H. Cai, Y. Wang, Y. Zhao, R. M. Sole, M. AguilO, F. Diaz, P. Camy, E. Dunina, A. Kornienko, U. Griebner, V. Petrov, and X. Mateos, "Growth, Spectroscopy and Laser Operation in Disordered $\mathrm{Tm}, \mathrm{Ho}: \mathrm{Ca}(\mathrm{Gd}, \mathrm{Lu}) \mathrm{AlO}_{4}$ Crystals," in Conference on Lasers and Electro-Optics (Optical Society of America, Washington, DC, 2020), p. SM3E.6.

15. Y. Zhao, L. Wang, W. Chen, Z. Pan, Y. Wang, P. Liu, X. Xu, Y. Liu, D. Shen, J. Zhang, M. Guina, X. Mateos, P. Loiko, Z. Wang, X. Xu, J. Xu, M. Mero, U. Griebner, and V. Petrov, "SESAM mode-locked Tm:LuYO ${ }_{3}$ ceramic laser generating 54-fs pulses at 2048 nm," Applied Optics 59, 10493-10497 (2020).

16. Y. Wang, W. Jing, P. Loiko, Y. Zhao, H. Huang, X. Mateos, S. Suomalainen, A. Härkönen, M. Guina, U. Griebner, and V. Petrov, "Sub-10 optical-cycle passively mode-locked $\mathrm{Tm}$ : $\left(\mathrm{Lu}_{2 / 3} \mathrm{Sc}_{1 / 3}\right)_{2} \mathrm{O}_{3}$ ceramic laser at 2 $\mu \mathrm{m}$," Optics Express 26, 10299-10304 (2018).

17. J. Paajaste, S. Suomalainen, A. Härkönen, U. Griebner, G. Steinmeyer, and M. Guina, "Absorption recovery dynamics in $2 \mu \mathrm{m}$ GaSbbased SESAMs," Journal of Physics D: Applied Physics 47, 065102 (2014).

18. F. Druon, M. Olivier, A. Jaffrès, P. Loiseau, N. Aubry, J. DidierJean, F. Balembois, B. Viana, and P. Georges, "Magic mode switching in $\mathrm{Yb}: \mathrm{CaGdAlO}_{4}$ laser under high pump power," Optics Letters 38, 4138-4141 (2013). 